\title{
Reinforced Aortic Root Reconstruction in Type A Aortic Dissection: A Prospective Study
}

\author{
Ahmed Elsharkawy, MD,${ }^{1}$ Ashraf A. El Midany, $\mathrm{MD},{ }^{2}$ Ahmed Elwakeel, $\mathrm{MD},{ }^{1}$ Eman Mahmoud, MD, ${ }^{3}$ \\ Ahmed K. Mohammed, MD, ${ }^{4}$ Sherif Nasr, MD $^{5}$ \\ ${ }^{1}$ Department of Cardiovascular \& Thoracic Surgery, Faculty of Medicine, Cairo University, Giza, Egypt; \\ ${ }^{2}$ Department of Cardiovascular \& Thoracic Surgery, Faculty of Medicine, Ain Shams University, Cairo, Egypt; \\ ${ }^{3}$ Department of Cardiology, Faculty of Medicine, Fayoum University, Fayoum, Egypt; \\ ${ }^{4}$ Department of Anesthesia, Surgical Intensive Care and Pain management, Faculty of Medicine, Cairo University, Giza, Egypt; \\ ${ }^{5}$ Department of Cardiovascular \& Thoracic Surgery, Faculty of Medicine, Fayoum University, Fayoum, Egypt
}

\section{ABSTRACT}

Background: Type A aortic dissection is a challenging surgical emergency associated with high morbidity and mortality. Many techniques have evolved to repair the dissected sinus segments and restore aortic valve dynamics. Herein, we evaluate the early outcome of a novel technique for reconstruction of dissected aortic root.

Methods: A prospective study was conducted on 300 patients to evaluate the early results of repair of dissected root in type A aortic dissection. The mean age was $59.65 \pm 8.52$ years, and $76 \%$ of patients were males. All patients had four standard steps for aortic reconstruction: 1) commissural resuspension; 2) right coronary sinus reinforcement with pericardial and Dacron bands; 3 ) non-coronary sinus reinforcement using external Dacron patch; 4) circumferential inversion of adventitial layer of the root. Patients were followed up clinically, echocardiographically, and by CT scan.

Results: The in-hospital mortality was $8 \%$. The mean cross-clamp time was $120 \pm 30$ minutes, and circulatory arrest time was $25+10$ minutes. Twenty-seven patients (9\%) experienced postoperative complications, including bleeding and acute kidney injury. During a mean follow-up time of $48 \pm 12$ months, there were no recurrent aortic dissection, aortic dilatation, pseudoaneurysm, or progression of aortic regurgitation during the entire study period.

Conclusions: This reconstructive technique technically is undemanding, feasible, safe, and durable with good early results. A larger cohort of patients with longer period of follow up should generate a more powerful evaluation of this technique.

Received fuly 8, 2021; accepted fuly 27, 2021.

Correspondence: Ashraf A.H. El Midany, MD, Department of Cardiovascular \& Thoracic Surgery; Ain Shams University Hospitals, Ramses Str. Abbassia, 11588, Cairo, Egypt, Telephone +2021006448285 (e-mail: ashelmidany@gmail.com).

\section{INTRODUCTION}

Acute type A aortic dissection (ATAAD) is one of the true cardiac emergencies that is associated with a high risk of perioperative mortality rates reaching up to $13-17 \%$ [Pape 2015; Mussa 2016].

The surgical management of aortic dissection is challenging and debatable to determine the appropriate proximal aortic root procedure. Several surgical techniques [Bentall 1968; David 1992; David 1995; Sarsam 1993; David 2007] have been evolved for the management of the aortic root in TAAD, including aortic root replacement or repair with either aortic valve sparing or valve replacement.

Given that the aortic apparatus, including the aortic annulus and leaflets, are not involved in most cases and due to complexity and technical difficulty of aggressive surgical aortic root replacement and risk of injury of the coronary arteries [Halstead 2005; Casselman 2000], aortic root reconstruction, using various surgical techniques including the external, internal, or intramural reinforcement with pros $\neg$ thetic, biologic, or autologous materials, have been applied as a reasonable option to preserve the aortic leaf-lets and function [Rylski 2013; Fleischman 2018; Tang 2017].

Herein, we describe a modified reinforced aortic root re $\neg$ construction approach for treating acute ATAAD, involving the aortic root, and evaluate the feasibility, effectiveness and safety of this approach.

\section{MATERIALS AND METHODS}

A prospective observational study was conducted between January 2011 and January 2018, on 300 consecutive patients, who were scheduled for surgery to repair ATAAD. Of these, 243 patients $(81 \%)$ were presenting with acute dissection.

All patients with ATAAD, involving the aortic root between the sinotubular junction and the aortic annulus and scheduled for the surgery, were included in the study. Exclusion criteria were pathologies not suitable for aortic root reconstruction, including aortic sinus aneurysm or aortic annulus dilatation; coronary artery tears or avulsions; moderate or severe aortic regurgitation caused by disorders other 
than dissec $\neg$ tion; and other aortic valve lesions not amenable for repair.

A detailed preoperative assessment of all patients was done, including the routine preoperative work up, lactate, and cardiac enzymes.

Transthoracic echocardiography (TTE) and transesophageal echocardiography were performed in all patients to evaluate aortic regurgitation and other valvular dysfunction and to iden $\neg$ tify the location of intimal tears and presence of coronary involvement.

Multi-slice computed tomography (MSCT) scan or magnetic resonance angiography (MRA) also were performed in cases of elevated serum creatinine to assess the extent of dissection of the aorta and the maximal diam $\neg$ eters of each segment of the aorta, including the aortic root.

In cases with severe hemodynamic instability, CT scans with contrast enhancement were performed on emergency basis, and intraoperative transesophageal echocardiography was conducted to evaluate valvular lesion and left ventricular function.

Surgical technique: All patients were operated via the standard median sternotomy. The cardiopulmonary bypass (CPB) was established by arterial cannulation of the axillary artery $(N=205)$, femoral artery $(N=80)$, both axillary and femoral arteries $(N=10)$, innominate artery $(N=3)$, or the distal ascending aorta true lumen $(N=2)$ and a dual-stage atriocaval cannula in the right atrium was used for venous cannulation.

In patients requiring arch reconstruction, cerebral protection was achieved by antegrade cerebral perfusion $(N=216)$ and retrograde cerebral perfusion $(N=36)$, as well as moderate hypothermia $(N=132)$ (esophageal temperature $>20^{\circ} \mathrm{C}$ ) or deep hypothermia $(N=52)$ (esophageal temperature $<20^{\circ} \mathrm{C}$ ) was introduced. Myocardial protection was achieved with intermittent antegrade cold blood cardioplegia $(N=228)$ and Custodiol solution $(N=72)$.

The aortic root carefully was explored to ensure the suitability for the reconstruction. The ascending aorta was transected at approximately $5 \mathrm{~mm}$ above the sinotubular junction. The tissue surrounding the aortic root carefully was dissected to ensure the integrity of the intima and the adventitia with removal of all thrombi in the dissected aortic layers. Then, aortic root reconstruction was conducted, including four main steps: (1) commissural resuspension with pledgeted $5 / 0$ polypropylene mattress sutures; (2) right coronary sinus reinforcement, using native pericardial band from the inner aortic wall and Dacron band from the outer wall, immediately above the right coronary ostium; (3) noncoronary sinus reinforcement, using external Dacron patch fashioned according to the shape of dissected sinus fixed to the base and commissures; (4) inversion of the adventitial layer of the whole root circumferentially using 5/0 running polypropylene sutures after trimming the media shorter than the adventitia. (Figure 1) (Figure 2) The proximal anastomosis with a Dacron graft then was sewn circumferentially to the reconstructed aorta.

In conjunction with ascending aortic replacement, total arch replacement and hemiarch replacement were performed in six patients (2\%) and 246 patients (82\%), respectively; concomitant

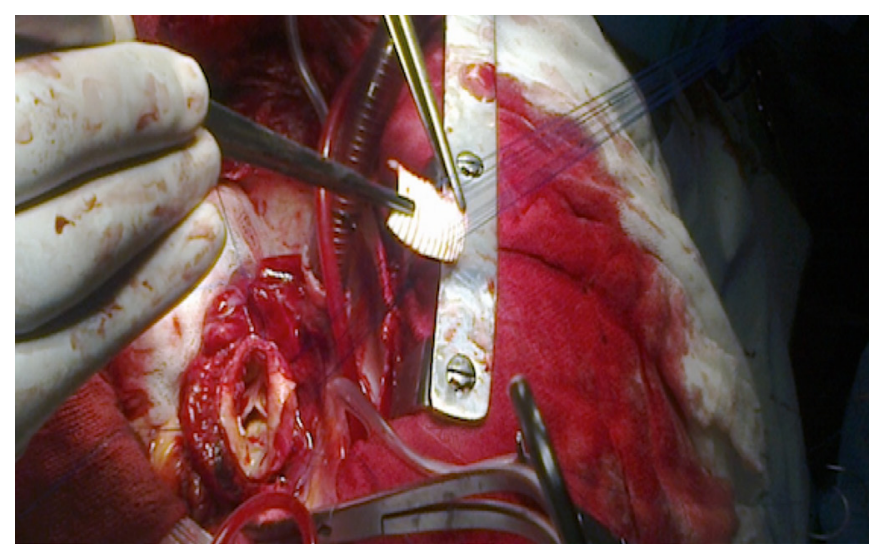

Figure 1. Operative view for fash-

ioning of external Dacron patch for reinforcement of the non-coronary sinus.

coronary artery bypass was performed in 18 patients $(6 \%)$.

All patients were followed up 3 and 6 months after surgery, and annually thereafter. Physical examinations were performed at outpatient clinics to check for the development of

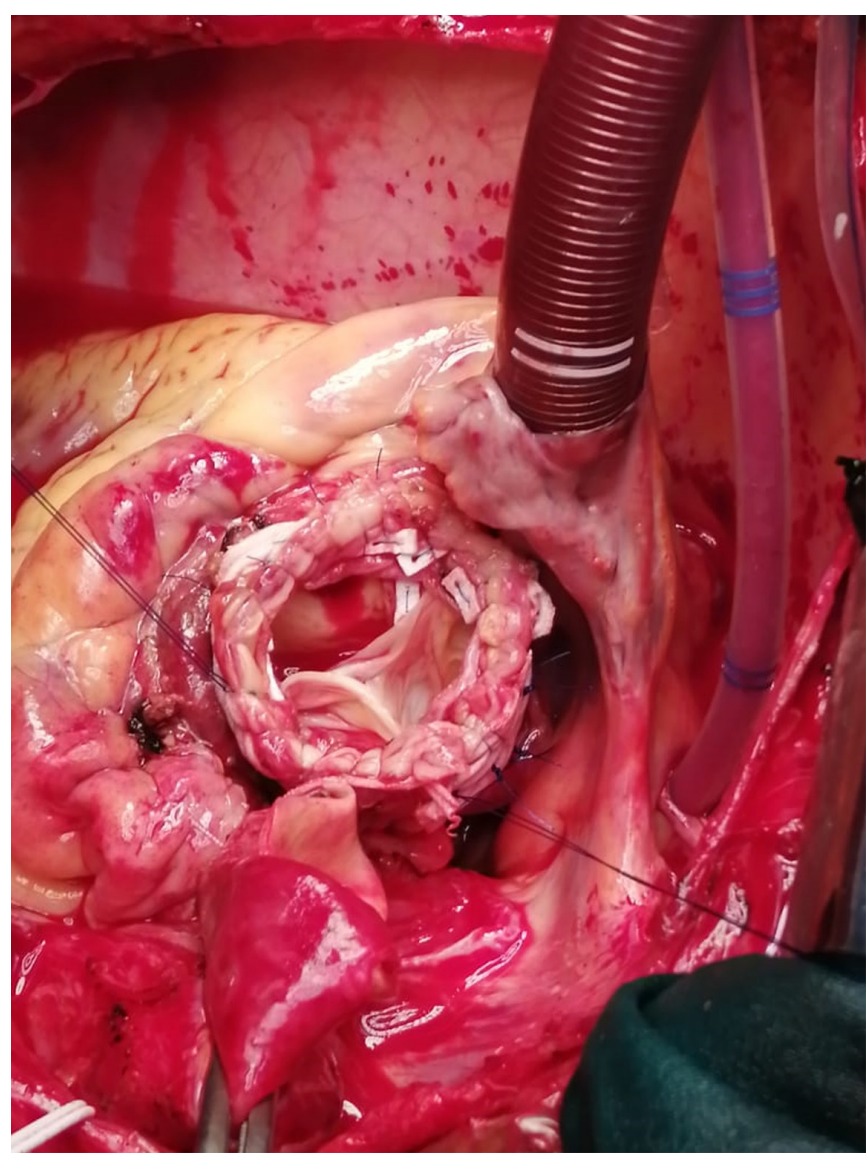

Figure 2. Operative view for the inversion of the adventitial layer of the whole root circumferentially using 5/0 running polypropylene sutures after trimming the media shorter than the adventitia. 
Table 1. Patient demographics and preoperative clinical characteristics

\begin{tabular}{|c|c|}
\hline & $\begin{array}{c}\text { Number of patients } \\
\qquad(N=300)\end{array}$ \\
\hline Age, years (mean $\pm S D)$ & $59.65 \pm 8.52$ \\
\hline \multicolumn{2}{|l|}{ Gender } \\
\hline Male & $228(76 \%)$ \\
\hline Female & $72(24 \%)$ \\
\hline \multicolumn{2}{|l|}{ Onset } \\
\hline Acute dissection ( $<1$ month) & $243(81 \%)$ \\
\hline Chronic dissection (>1 month) & $57(19 \%)$ \\
\hline \multicolumn{2}{|l|}{ Risk factors } \\
\hline Hypertension & $300(100 \%)$ \\
\hline Osteogenesis imperfecta & $3(1 \%)$ \\
\hline Previous TEVAR & $12(4 \%)$ \\
\hline Cerebral malperfusion & $3(1 \%)$ \\
\hline Renal malperfusion & $9(3 \%)$ \\
\hline Lower limb malperfusion & $12(4 \%)$ \\
\hline Paraplegia & $6(2 \%)$ \\
\hline \multicolumn{2}{|l|}{ Preoperative echo data } \\
\hline Pericardial effusion & $30(10 \%)$ \\
\hline Bicuspid aortic valve & $12(4 \%)$ \\
\hline \multicolumn{2}{|l|}{ Aortic regurgitation degree } \\
\hline Moderate & $204(68 \%)$ \\
\hline Severe & $96(32 \%)$ \\
\hline \multicolumn{2}{|l|}{ Preop MSCT (Aorta and Coronary): } \\
\hline \multicolumn{2}{|l|}{ Dissection extent } \\
\hline $\begin{array}{l}\text { Dissection involves the ascending aorta, } \\
\text { aortic arch, and descending aorta }\end{array}$ & $282(94 \%)$ \\
\hline Dissection is confined to the ascending aorta & $18(6 \%)$ \\
\hline Intramural Hematoma type A & $27(9 \%)$ \\
\hline Aberrant right subclavian artery & $6(2 \%)$ \\
\hline Bovine arch & $12(4 \%)$ \\
\hline Retrograde dissection type $\mathrm{A}$ & $18(6 \%)$ \\
\hline LAD coronary lesion & $9(3 \%)$ \\
\hline Anomalous origin of right coronary artery & $3(1 \%)$ \\
\hline
\end{tabular}

TEVAR, thoracic endovascular aortic repair; MSCT, multislice computed tomography; LAD, left anterior descending artery

aortic regurgitation (AR). Transthoracic echocardiography and contrast-enhanced computed tomographic (CT) scans were performed, before discharge as well as at follow up, to evaluate the aortic root reconstruction and whether there were any recurrent dissection, aneurysm, or pseudoaneurysm as well as the grade of aortic valve regurgitation and cardiac function.

Our measured outcomes included postoperative mortality, complications, and the progression of AR after surgery.
Statistical analysis: Continuous variables were expressed as mean and standard deviation and analyzed using the unpaired t-test. Categorical variables were expressed as number and percentage. $P$-value of less than 0.05 was considered statistically significant. Survival, freedom from reoperation, and freedom from moderate or severe aortic valve regurgitation were analyzed by the Kaplan- Meier method.

\section{RESULTS}

The mean age was $59.65 \pm 8.52$ years. Most of the patients were males (76\%). Bicuspid aortic valve was present in 12 patients (4\%). Osteogenesis imperfecta was observed in three patients (1\%). All patients were suffering systemic hypertension. Twelve patients (4\%) had undergone previous TEVAR. Malperfusion syndromes were evident in 30 patients $(10 \%)$ and 18 patients $(6 \%)$ were operated on in cardiogenic shock, due to massive pericardial effusion. Preoperative severe aortic valve regurgitation was present in 96 patients (32\%). The demographic and preoperative data of these patients are shown in Table 1. (Table 1)

The mean cardiopulmonary bypass time was $120 \pm 30 \mathrm{~min}$, mean cross-clamp time was $160 \pm 20 \mathrm{~min}$, and mean circulatory arrest time was $25 \pm 10 \mathrm{~min}$. Surgical details and concomitant procedures are given in Table 2. (Table 2)

Postoperatively, 15 patients (5\%) required chest re-exploration for bleeding and three of them required packing with delayed sternal closure. Twelve patients (4\%) experienced postoperative acute renal failure that required temporary hemodialysis. No stroke or persistent neurologic disorders occurred. Mild aortic regurgitation was observed in 49 patients $(16.3 \%)$, and there was no AR in other patients.

The in-hospital mortality was 24 patients $(8 \%)$. The reasons for in-hospital death were multisystem organ failure in 12 patients (4\%), heart failure in eight patients (2.6\%), and sepsis in four patients (1.3\%). Postoperative data was summarized in Table 3. (Table 3)

During a mean follow up of $48 \pm 12$ months, there were no late mortalities, echocardiography showed no progression of AR, CT scan showed normal aortic root without leak or dissection around the sinus of Valsalva, and all patients were free from reoperation.

\section{DISCUSSION}

Reconstruction of aortic root in cases of acute type A aortic dissection (ATAAD) requires a comprehensive evaluation of the severity of the pathology, patient demographics, and comorbidities at the time of the operative intervention.

In most of cases presenting with ATAAD, the primary intimal tear is located in the ascending aorta with extension of the dissection flap into the non-coronary cusp rather than the left and right coronary sinuses with preservation of the aortic valve cusps or annulus. The aortic regurgitation associated with ATAAD is due to disruption of the aortic wall architecture with concomitant unhinging of one or more of the aortic valve commissures, resulting in cusp prolapse rather than primary leaflet pathology. Therefore, the dissected aortic root 
Table 2. Operative data

\begin{tabular}{|c|c|}
\hline & Number (\%), mean \pm SD \\
\hline \multicolumn{2}{|l|}{ Timing of operation } \\
\hline Elective & $57(19 \%)$ \\
\hline Emergency & $243(81 \%)$ \\
\hline \multicolumn{2}{|l|}{ Arterial inflow } \\
\hline Axillary artery & $205(68.3 \%)$ \\
\hline Femoral artery & $80(26.6 \%)$ \\
\hline Ascending aorta (central cannulation) & $3(1 \%)$ \\
\hline Innominate artery & $2(0.6 \%)$ \\
\hline Combined axillary and femoral artery & $10(3.3 \%)$ \\
\hline Cardiopulmonary bypass duration (minutes) & $160 \pm 20$ \\
\hline Cross-clamp duration (minutes) & $120 \pm 30$ \\
\hline Total circulatory arrest time (minutes) & $25 \pm 10$ \\
\hline \multicolumn{2}{|l|}{ Cerebral perfusion } \\
\hline Antegrade & $216(72 \%)$ \\
\hline Retrograde & $36(12 \%)$ \\
\hline \multicolumn{2}{|l|}{ Associated procedure } \\
\hline Mitral repair & $3(1 \%)$ \\
\hline CABG & $18(6 \%)$ \\
\hline Femoro femoral bypass & $3(1 \%)$ \\
\hline lliac stent & $3(1 \%)$ \\
\hline \multicolumn{2}{|l|}{ Associated arch procedure } \\
\hline Hemi arch replacement & $246(82 \%)$ \\
\hline Elephant trunk procedure & $6(2 \%)$ \\
\hline
\end{tabular}

can be repaired with resuspension of the aortic valve commissures to restore aortic valve competency [Leshnower 2016].

Several techniques have been reported to spare the aortic valve. David et al. [David 1995] first performed the partial aortic root repair to correct the non-coronary sinus dissection in dilated aortic root. Komiya et al. [Komiya 2008] performed the modification of partial aortic root remodeling by fixing a U-shaped Dacron patch in the sinus in patients with ATAAD. Tang and coworkers [Tang 2017] reported modi-fied sandwich repair of aortic root that consists of internal and external layers of Teflon felt that are incorporated into the supracoronary aortic graft anastomosis with low in-hospital mortality and low long-term reoperation rates.

Han et al. [Han 2013] described an aortic root reconstructive approach, including the insertion of an autologous pericar $\neg$ dial patch in the false lumen, lining of the STJ lumen with a polyester vascular ring and wrapping the vessel with Teflon strips for reinforcement with low rates of in-hospi-tal/ follow-up mortality and postoperative complications.

There is no doubt about the theoretical advantages of root preservation, including avoidance of coronary artery manipulation, less cross-clamp and cardiopulmonary bypass times, and elimination of prosthetic valve insertion and its related
Table 3. Postoperative data

\begin{tabular}{lc}
\hline & Number (\%), mean \pm SD \\
\hline Mechanical ventilation duration (hours) & $4 \pm 72$ \\
ICU stay duration (hours) & $84 \pm 12$ \\
Hospital stay duration (days) & $13.2 \pm 3.6$ \\
Re-exploration for bleeding & $15(5 \%)$ \\
Packing and delayed sternal closure & $3(1 \%)$ \\
Acute renal failure requiring dialysis & $12(4 \%)$ \\
Mortality & $24(8 \%)$
\end{tabular}

potential adverse events of endocarditis and permanent need for anticoagulation. However, the potential risk for recurrent aortic dissection, aortic valve insufficiency, dilatation of aortic root, and pseudoaneurysm makes the freedom from aortic root reoperation in follow up questionable.

Freedom from aortic root reoperation in patients, who have undergone aortic root reconstruction for ATAAD, has been reported to be between $69 \%$ and $95 \%$ at 10 years [Rylski 2013; Von Segesser 1996; Mazzucotelli 1993; Rylski 2014]. On the other hand, Han et al. [Han 2013] reported that none of their patients experienced postoperative recurrent aortic dissection, aortic aneurysm, or pseudoaneurysm and they attributed that to their reinforcement technique, which eliminated the intimal and adventitial fragility and prevented blood exudation into the extravascular space or formation of pseudoaneurysm under the adventitia.

Herein, we report a novel surgical reinforcement technique of the aortic root performed in 300 patients with ATAAD. The key steps of this technique include the use of native pericardial band from the inner aortic wall and Dacron band from the outer wall for right coronary sinus reinforcement; noncoronary sinus reinforcement by the use of external Dacron patch fixed to the base and commissures; in addition to the inversion of the adventitial layer of the whole root circumferentially after trimming the media shorter than the adventitia. Although there was $8 \%$ in-hospital postoperative mortality, there were no postoperative recurrent aortic dissection, aortic dilatation, pseudoaneu $\neg$ rysm or aortic valve regurgitation during the mean follow-up period of $48 \pm 12$ months.

\section{CONCLUSION}

Based on the available literature, there is a lack of consensus as to the optimal surgi-cal reconstructive approach for the treatment of ATAAD involving the aortic root. Our approach is safe, durable, does not need advanced techniques and extra manipulations or root dissection in presence of tissue hematoma, with short myocardial ischemic time, hence, reducing the operative complexity and shortening of the operative time.

However, due to the potential risk for aortic root dilatation, aortic valve insufficiency, and pseudoaneurysm of these reconstructive techniques, we recommend an individualized 
assessment for the most appropriate proximal aortic root procedure in every patient with ATAAD to reduce the perioperative mortality rate and improve the long-term outcome.

Our study has some limitations that do not allow making a definitive statement. The number of patients is small, the follow-up data is limited to short and mid-term data, and the study does not compare the risk factors or low rate of adverse outcomes to other alternative techniques. Thus, larger cohort studies and longer follow up are needed. In addition, comparative studies are warranted to determine the effectiveness and outcome differences in favor of this technique or its alternatives.

\section{REFERENCES}

Bentall H, De Bono A. 1968. A technique for complete replacement of the ascending aorta. Thorax. 23(4):338-9.

Casselman FP, Tan ES, Vermeulen FE, Kelder JC, Morshuis WJ, Schepens MA. 2000. Durability of aortic valve preservation and root reconstruction in acute type A aortic dissection. Ann Thorac Surg. 70:1227-33.

David TE, Feindel CM. 1992. An aortic valve-sparing operation for patients with aortic incompetence and aneurysm of the ascending aorta. J Thorac Cardiovasc Surg. 103(4):617-622.

David TE, Feindel CM, Armstrong S, Maganti M. 2007. Replacement of the ascending aorta with reduction of the diameter of the sinotubular junctionto treat aortic insufficiency in patients with ascending aortic aneurysm. J Thorac Cardiovasc Surg. 133(2):414-418.

David TE, Feindel CM, Bos J. 1995. Repair of the aortic valve in patients with aortic insufficiency and aortic root aneurysm. J Thorac Cardiovasc Surg. 109(2):345-351.

Fleischman F, Elsayed RS, Cohen RG, et al. 2018. Selective Aortic Arch and Root Replacement in Repair of Acute Type A Aortic Dissection. Ann Thorac Surg. 105(2):505-512.

Halstead JC, Spielvogel D, Meier DM, et al. 2005. Composite aortic root replacement in acute type A dissection: time to rethink the indications? Eur J Cardiothorac Surg. 27:626-32.

Han Q, Song Z, Zou L, et al. 2013. Reinforced aortic root reconstruction for acute type A aortic dissection involving the aortic root. Rev Bras Cir Cardiovasc. 28(2):190-9.

Komiya T, Tamura N, Sakaguchi G, et al. 2008. Modified partial aortic root remodeling in acute type A aortic dissection. Interact Cardiovasc Thorac Surg. 8(3):306-309.

Leshnower BG, Chen EP. 2016. When and how to replace the aortic root in type A aortic dissection. Ann Cardiothorac Surg. 5(4):377-382.

Mazzucotelli JP, Deleuze PH, Baufreton C, et al. 1993. Preservation of the aortic valve in acute aortic dissection: long-term echocardiographic assessment and clinical outcome. Ann Thorac Surg. 55:1513-7.

Mussa FF, Horton JD, Moridzadeh R, et al. 2016. Acute aortic dissection and intramural hematoma: a systematic review. JAMA. 316 (7):754-63.

Pape LA, Awais M, Woznicki EM, et al. 2015. Presentation, Diagno $\neg$ sis, and Outcomes of Acute Aortic Dissection: 17-Year Trends from the International Registry of Acute Aortic Dissection. JACC. 66(4):350-358.

Rylski B, Bavaria JE, Milewski RK, et al. 2014. Long-Term Results of Neomedia Sinus Valsalva Repair in 489 Patients with Type A Aortic Dissection. Ann Thorac Surg. 98:582-9.

Rylski B, Beyersdorf F, Blanke P, et al. 2013. Supracoronary ascending aortic replacement in patients with acute aortic dissection type A: what happens to the aortic root in the long run? J Thorac Cardiovasc Surg. 146:285-90.

Sarsam MA, Yacoub M. 1993. Remodeling of the aortic valve anulus. J Thorac Cardiovasc Surg. 105(3):435-438.

Tang Y, Liao Z, Han L, Tang H, et al. 2017. Long-term results of modiᄀfied sandwich repair of aortic root in 151 patients with acute type A aortic dissection. Interact CardioVasc Thorac Surg. 25 (1):109-13.

Von Segesser LK, Lorenzetti E, Lachat M, et al. 1996. Aortic valve preservation in acute type A dissection: is it sound? J Thorac Cardiovasc Surg. 111:381-91. 